\title{
Downregulation of PTPRH (Sap-1) in colorectal tumors
}

\author{
MATEUSZ BUJKO ${ }^{1}$, PAULINA KOBER ${ }^{1}$, MAŁGORZATA STATKIEWICZ ${ }^{2}$, \\ MICHAL MIKULA ${ }^{2}$, EMILIA GRECKA ${ }^{1}$, NATALIIA RUSETSKA ${ }^{1}$, MARCIN LIGAJ $^{3}$, \\ JERZY OSTROWSKI ${ }^{2}$ and JANUSZ ALEKSANDER SIEDLECKI ${ }^{1}$
}

\author{
Departments of ${ }^{1}$ Molecular and Translational Oncology, ${ }^{2}$ Genetics and ${ }^{3}$ Pathology and Laboratory Diagnostics, \\ Maria Sklodowska-Curie Memorial Cancer Center and Institute of Oncology, Warsaw, Poland
}

Received February 14, 2017; Accepted June 13, 2017

DOI: 10.3892/ijo.2017.4068

\begin{abstract}
Tyrosine phosphorylation is one of the basic mechanisms for signal transduction in the cell. Receptors exhibiting tyrosine kinase activity are widely involved in carcinogenesis and are negatively regulated by receptor protein tyrosine phosphatases (RPTP). Genes encoding different RPTPs are affected by aberrant epigenetic regulation in cancer. PTPRH (SAP-1) has been previously described to be overexpressed in colorectal cancer (CRC) and classified as an oncogenic factor. Previous microarray-based mRNA expression comparison of colorectal adenomas (AD), CRC and normal mucosa samples (NM) demonstrated that PTPRH tumor expression is the most reduced of all RPTP genes. qRT-PCR validation revealed gene downregulation for CRC (7.6-fold-change; $\mathrm{P}<0.0001)$ and $\mathrm{AD}(3.4$-fold-change; $\mathrm{P}<0.0001)$ compared to NM. This was confirmed by immunohistochemical staining of tumor and NM sections as pronounced decrease of protein expression was observed in CRCs compared to the corresponding normal tissue. DNA methylation of two PTPRH promoter fragments was analyzed by pyrosequencing in a group of CRC, and AD patients as well as NM samples and CRC cell lines. The mean DNA methylation levels of these two regions were significantly higher in CRC than in NM.
\end{abstract}

Correspondence to: Dr Mateusz Bujko, Department of Molecular and Translational Oncology, Maria Sklodowska-Curie Memorial Cancer Center and Institute of Oncology, 5 W.K. Roentgena, 02-781 Warsaw, Poland

E-mail: mbujko@coi.waw.pl

Abbreviations: RTK, receptor tyrosine kinase; PTP, protein tyrosine phosphatase; RPTP, receptor protein tyrosine phosphatase; CRC, colorectal cancer; AD, colorectal adenoma; qRT-PCR, quantitative real-time PCR; IHC, immunohistochemistry; ChIP, chromatin immunoprecipitation; Pol2, RNA II polymerase; H3K4m3, tri-methylation of histone $\mathrm{H} 3$ at lysine $4 ; \mathrm{H} 3 \mathrm{~K} 27 \mathrm{~m} 3$, tri-methylation of histone $\mathrm{H} 3$ at lysine 27; $\mathrm{Ab}$, antibody; TSS, transcription start site; 5-aza-dC, 5-aza-2'-deoxycytidine; SDS-PAGE, sodium dodecyl sulphate-polyacrylamide gel electrophoresis

Key words: PTPRH, SAP-1, tyrosine phosphatase, epigenetic, gene expression, DNA methylation, colorectal tumor, adenoma, adenocarcinoma
Both regions were highly methylated in SW480 and HCT116 cell lines contrary to unmethylated HT29 and COLO205. Cell lines with highly methylated promoters notably showed lower PTPRH expression levels, lower RNA II polymerase concentrations and higher levels of H3K27 trimethylation in the promoter and gene body, measured by chromatin immunoprecipitation. Cells were cultured with 5-aza-deoxycitidine and an increase in PTPRH expression was observed in SW480 and HCT116, whereas this was unchanged in the unmethylated cell lines. The results indicate that PTPRH is downregulated in colorectal tumors and its expression is epigenetically regulated via DNA methylation and chromatin modifications.

\section{Introduction}

Phosphorylation of tyrosine is one of the most common posttranslational modifications of proteins. It plays a special role in the modulation of the dynamics of protein function and is essential for signal transduction in the cell (1). Receptor tyrosine kinases (RTKs) are a large superfamily of proteins including many of those involved in tumorigenesis, such as EGFR or SRC (2). These receptors are targets for extracellular ligand molecules that trigger receptor activation and downstream signal transduction. This class of receptors is negatively regulated by protein phosphatases (3). They are large functional class of approximately 140 human proteins that evolved from distinct genes and differ in enzymatic mechanisms (3). They are historically divided, based on substrate specificity into two classes, protein Ser/Thr phosphatases and protein tyrosine phosphatases (PTPs) (3). Receptor protein tyrosine phosphatases (RPTPs) are the class of PTPs that besides the tyrosine phosphatase domains possess CAM-like extracellular regions anchoring these proteins at cell membrane. Twenty-one RPTPs encoded by human genome play a role in variable cellular processes (4).

In cancer cells, stimulation of oncogenic RTKs is a key element for activating the variable cancer-related processes involving cell proliferation or angiogenesis (2) and therefore receptor PTPs have been considered by default as potential tumor suppressors $(5,6)$. Studies that have focused on colorectal cancer (CRC) show the suppressive role of some RPTPs including PTPRT (7) and PTPRJ $(6,8)$. In CRC, somatic frameshift DNA mutations have been found in different genes encoding this class of proteins: PTPRT, PTPRF, PTPRG (9) 
as well as in PTPRA, PTPRE and PTPRS (10), whereas deletions were observed in $P T P R J$ (11). Genes encoding receptor PTPs were also observed to be affected by aberrant epigenetic regulation. CRC-related promoter DNA hypermethylation was found in PTPRG (12) PTPRD (13) as well as in PTPRM, PTPRT, PTPRR and PTPRZI (14).

In contrast to most RPTPs, PTPRH, which is also known as stomach cancer-associated protein tyrosine phosphatase-1 (SAP-1), is found to be overexpressed in CRC (15) and is suggested to act as an oncogenic factor (5). This observation is somewhat inconsistent with the fact that this PTP is closely similar to the structure of PTPRJ, which is a welldocumented tumor suppressor that binds to EGFR, and plays a role in MAPK regulation as well as PKB/AKT signaling $(6,8)$. Functional experiments on PTPRH activity also suggest that its role is rather suppressive than oncogenic $(16,17)$.

Our study was provoked because in previous mRNA expression genome-wide profiling of colorectal normal mucosa samples, adenomas and CRCs, PTPRH was found among genes notably downregulated in tumor tissue, contrary to previously reported overexpression (18). We measured mRNA and protein expression levels in normal mucosa, adenoma and cancer samples as well as in CRC cell lines by qRT-PCR and immunohistochemistry (IHC) and sought for a role of aberrant epigenetic regulation in PTPRH downregulation.

\section{Materials and methods}

Patients and tissue samples. Gene expression analysis by quantitative qRT-PCR was performed on fresh frozen tissue samples obtained from 26 CRC patients, 24 samples of corresponding normal mucosa sections and 42 colorectal adenoma samples. Cryostat sections were prepared from each specimen using a Microm HM 505E (Zeiss) and upper and lower sections from each cryosection set were evaluated by a pathologist for relative cell type content.

Formalin-fixed and paraffin-embedded tissue from 24 CRC and $12 \mathrm{AD}$ samples was used for DNA isolation and DNA methylation assessment, whereas 14 of the CRC samples with matched normal colonic mucosa sections, along with $10 \mathrm{AD}$ samples, were used for immunohistochemical evaluation.

Ten additional samples of non-neoplastic colonic epithelia obtained from normal tissue areas on the margins of resected colorectal tumors were collected from 10 anonymous patients by scraping the colonic epithelial layers with plastic swab sticks. The samples were used for DNA isolation and served as controls in DNA methylation analysis.

Clinical tissue specimens were collected at the Maria Sklodowska-Curie Memorial Cancer Center and Institute of Oncology in Warsaw in accordance with local ethics committee approval and individual patients' informed consent. Patient characteristics are presented in Table I.

Cell lines culture and 5-aza-2'-deoxycytidine (5-aza-dC) treatment. HCT 116 and HT29 cell lines were cultured in McCoy's 5A medium (Sigma-Aldrich Inc., St. Louis, MO, USA) supplemented with $10 \%$ fetal bovine serum. SW480 and COLO-205 cell lines were cultured in RPMI-1640 medium (Sigma-Aldrich Inc.) supplemented with 5\% and 10\% fetal bovine serum, respectively. The Caco- 2 cell line was cultured
Table I. Patient characteristics.

\begin{tabular}{|c|c|c|c|}
\hline Characteristics & $\begin{array}{l}\text { Expression } \\
\text { qRT-PCR }\end{array}$ & $\begin{array}{c}\text { Expression } \\
\text { IHC }\end{array}$ & $\begin{array}{c}\text { DNA methylation } \\
\text { pyrosequencing }\end{array}$ \\
\hline \multicolumn{4}{|l|}{ Cancer patients } \\
\hline Number of patients & 26 & 14 & 24 \\
\hline \multicolumn{4}{|l|}{ Sex (no. of patients) } \\
\hline Male & 11 & 6 & 10 \\
\hline Female & 15 & 8 & 14 \\
\hline \multicolumn{4}{|l|}{ Age (years) } \\
\hline Range & $38-82$ & $38-78$ & $38-82$ \\
\hline Median & 64 & 67 & 63.5 \\
\hline \multicolumn{4}{|c|}{ Astler-Coller's stage (no. of patients) } \\
\hline B1 & 4 & 3 & 4 \\
\hline B2 & 15 & 8 & 13 \\
\hline B3 & 7 & 3 & 7 \\
\hline \multicolumn{4}{|l|}{ Adenoma patients } \\
\hline Number of patients & 42 & 12 & 12 \\
\hline \multicolumn{4}{|l|}{ Sex (no. of patients) } \\
\hline Male & 25 & 6 & 6 \\
\hline Female & 17 & 6 & 6 \\
\hline \multicolumn{4}{|l|}{ Age (years) } \\
\hline Range & $41-83$ & $42-80$ & $42-80$ \\
\hline Median & 60 & 61.5 & 61.5 \\
\hline \multicolumn{4}{|l|}{ Size (mm) } \\
\hline Range & $9-50$ & $10-50$ & $10-50$ \\
\hline Median & 15 & 16 & 16 \\
\hline \multicolumn{4}{|c|}{ Histopathology (no. of patients) } \\
\hline Tubular AD & 29 & 5 & 5 \\
\hline Tubulo-villous AD & 13 & 7 & 7 \\
\hline \multicolumn{4}{|l|}{ Normal mucosa } \\
\hline Number of samples & 24 & 14 & 10 \\
\hline \multicolumn{4}{|l|}{ Sex (no. of patients) } \\
\hline Male & 11 & 6 & 6 \\
\hline Female & 13 & 8 & 4 \\
\hline \multicolumn{4}{|l|}{ Age (years) } \\
\hline Range & $38-82^{\mathrm{a}}$ & $38-78$ & $43-80$ \\
\hline Median & $62^{\mathrm{a}}$ & 67 & 59 \\
\hline
\end{tabular}

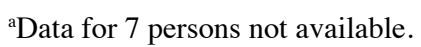

in MEM medium (Sigma-Aldrich Inc.) supplemented with $20 \%$ fetal bovine serum (Gibco). All culture media contained $1 \%$ antibiotics (PenStrep, Gibco). Cell culture was performed at $37^{\circ} \mathrm{C}$ in a humidified $5 \% \mathrm{CO}_{2}$ atmosphere. The cells were grown in culture medium until $50 \%$ confluence and subsequently treated with $0,2.5,5$ and $10 \mu \mathrm{M} 5$-aza-2'-deoxycytidine (Abcam, Cambridge, MA, USA) for 3 days. The medium containing 5-aza-dC was refreshed daily.

Real-time PCR expression assessment. Relative PTPRH expression was assessed with qRT-PCR with respect to MIQE 
guidelines (19). Total RNA from tissue samples and cell lines was isolated using RNeasy Mini (Qiagen) and quantified with NanoDrop 2000 Spectrophotometer (Thermo Fisher Scientific, Waltham, MA, USA). RNA samples were checked for quality on the Agilent 2100 Bioanalyzer and samples with RIN $>7$ were included. Each RNA sample $(1 \mu \mathrm{g})$ was subjected to reverse transcription with SuperScript II Reverse Transcriptase (Invitrogen) using both random hexamer and oligo dT, according to manufacturer's protocol. qRT-PCR was carried out using a 384-well format and an Applied Biosystems 7900HT Fast Real-time PCR System (Applied Biosystems) with Sensimix SYBR kit (Bioline), according to manufacturers' instructions in a volume of $5 \mu \mathrm{l}$. RT-qPCR was performed using the following cycling conditions: $95^{\circ} \mathrm{C}$ for $10 \mathrm{~min}$ followed by 40 cycles of $95^{\circ} \mathrm{C}$ for $15 \mathrm{sec}$ and $60^{\circ} \mathrm{C}$ for 45 with subsequent dissociation curve protocol. $A C T B$ ( $\beta$-actin) was selected as a reference gene after a previous evaluation of 4 potential reference genes: $A C T B$, $U B C, R P L P O, G A P D H$ with GeNorm software (20). The standard curves based on amplifying known cDNA template concentrations were used for assessment of PCR efficiency and linear dynamic range. Normalized PTPRH expression was calculated using Q-gene software (21). Primer sequences are listed in Table II.

Immunohistochemistry. Immunohistochemical staining was performed on $4-\mu \mathrm{m}$ formalin-fixed, paraffin-embedded tissue sections of CRCs and matched normal mucosa from 14 patients as well as 14 colorectal adenomas using the Envision Detection System (Dako). Sections were deparaffinized with xylene and rehydrated in a series ethanol solutions of decreasing concentration. Heat-induced epitope retrieval was carried out in a Target Retrieval Solution pH 9.0 (Dako) in a $96^{\circ} \mathrm{C}$ water bath, for $20 \mathrm{~min}$. After cooling the retrieval solutions for $25 \mathrm{~min}$ at room temperature, the slides were treated for 5 min with a Blocker of Endogenous Peroxidase (Dako). Slides were incubated with polyclonal antibody (Ab) against PTPRH (PA5-31340, dilution 1:200) (Thermo Fisher Scientific) for $30 \mathrm{~min}$ at room temperature and subsequently labelled with the Envision Detection System (Dako). The color reaction product was developed with 3,3'-diaminobenzidine, tetrahydrochloride (Dako) as a substrate, and nuclear contrast was achieved with hematoxylin counterstaining. Staining intensity was assessed by a four-grade scale: 0 , lack of expression; 1 , weak expression; 2 , moderate expression; and 3 , strong expression. The stained tissue slides were examined by the pathologist who was blinded to the qRT-PCR results.

Western blotting. Cell pellets were resuspended in ice-cold RIPA buffer, incubated for $30 \mathrm{~min}$ in $4^{\circ} \mathrm{C}$ and centrifuged at $12500 \mathrm{rpm}$ for $20 \mathrm{~min}$ at $4^{\circ} \mathrm{C}$. Samples were resolved using SDS-PAGE and electrotransferred to polyvinylidene fluoride membranes (EMD Millipore). PTPRH was detected with polyclonal anti-PTPRH Ab (Pierce PA5-31340 PTPRH Rabbit polyclonal Ab, Pierce; Thermo Fisher Scientific), and a secondary Ab conjugated to HRP (\#31460, Pierce; Thermo Fisher Scientific). Detection of $\beta$-actin with mouse HRP conjugated mAb (8H10D10) (Cell Signalling, \#12262) served as control. Detection was performed by the enhanced chemiluminescence method (Pierce; Thermo Fisher Scientific).
DNA methylation analysis. DNA methylation levels of two 5' PTPRH regions [-190 to -253 upstream and +57 to +147 downstream from transcription start site (TSS)] were measured in CRC cell lines as well as in $14 \mathrm{CRC}, 14 \mathrm{AD}$ and 10 normal mucosa samples (obtained from swabs of normal colon epithelium) using the pyrosequencing assay according to the published protocol (22). DNA was isolated with the QIAamp DNA Mini kit (Qiagen) and bisulfite converted using the EpiTect kit (Qiagen), according to manufacturer's instructions. The PCR reaction was performed in a $30 \mu \mathrm{l}$ mixture containing 1X PCR buffer, $2 \mathrm{mM} \mathrm{MgCl}_{2}, 0.25 \mathrm{mM}$ dNTPs, $0.2 \mu \mathrm{M}$ of each primer, 0.5 units of FastStart DNA Polymerase (Roche Applied Science) under the following conditions: $94^{\circ} \mathrm{C}$ for $3 \mathrm{~min}$, with subsequent 40 cycles of $30 \mathrm{sec}$ at $94^{\circ} \mathrm{C}, 30 \mathrm{sec}$ at the annealing $52^{\circ} \mathrm{C}$ temperature and $30 \mathrm{sec}$ at $72^{\circ} \mathrm{C}$ and final elongation for $7 \mathrm{~min}$ at $72^{\circ} \mathrm{C}$. The primer sequences are listed in Table II.

The PCR products were purified and analyzed using the PyroMark Q24 System (Biotage AB, Uppsala, Sweden), according to manufacturer's instructions. For every particular sample the average methylation level of all CpGs within each analyzed region was calculated and used for comparing the sample groups.

Chromatin immunoprecipitation (ChIP) assay. The cells were cross-linked for $10 \mathrm{~min}$ at room temperature by adding formaldehyde directly to culture medium (final concentration 1\%), then formaldehyde was quenched at room temperature for 5 min with glycine at $125 \mathrm{mM}$ concentration. Fixed cells were suspended in $100 \mu \mathrm{l}$ of hypotonic buffer A with NP-40 detergent (10 mM HEPES pH 7.9, $2 \mathrm{mM} \mathrm{MgCl} 2,2 \mathrm{mM} \mathrm{KCl}$, NP-40 0.5\%) supplemented with protease and phosphatase inhibitors (Thermo Fisher Scientific; 78441) and incubated on ice for $5 \mathrm{~min}$ followed by centrifugation at $2000 \mathrm{rpm}$ for $5 \mathrm{~min}$ in $4^{\circ} \mathrm{C}$. Next, nuclei pellets were resuspended in lysis buffer (12.5 mM Tris-HCl, pH 8.0; 2.5 mM EDTA; $0.25 \%$ SDS) containing protease and phosphatase inhibitors (Thermo Fisher Scientific; 78441). Chromatin was sheared in a Bioruptor Plus (Diagenode) using the following protocol: $30 \mathrm{sec}$ on-off cycles for $10 \mathrm{~min}$ at high intensity. ChIP assays were done using the Matrix-ChIP on polypropylene plates (23). ChIP DNA data were expressed as percent of input DNA, or as the ratio of modified histone to total histone H3 (24). The following antibodies were used in ChIP assay: non-specific rabbit IgG (I-1000, Vector Laboratories), Pol2 (4H8) (Santa Cruz; sc-47701), Histone H3 (Abcam, ab1791), H3K4me3 (Diagenode; pAb-003-050), H3K27me3 (Millipore, 07-449). PCR primers for PTPRH promoter and 3 ' regions (exon 20) were used as well as primers for two control promoter regions of transcriptionally active $(A C T B)$ and inactive $(H B B)$ genes. Primer sequences are listed in Table II.

Statistical analysis. Gene expression values and DNA methylation levels were compared using the two-sided MannWhitney U test. A significance threshold level of $\alpha=0.05$ was adopted. Data were analyzed and visualized by GraphPad Prism (GraphPad Software). Microarray data stored in the Gene Expression Omnibus (GEO) were analyzed using GEO2R, being an interactive web tool integrated into the GEO service (25). 
Table II. Sequences of PCR primers.

\begin{tabular}{|c|c|c|c|}
\hline Gene symbol & PCR primer sequence $5^{\prime} \rightarrow 3^{\prime}$ & $\begin{array}{l}\text { Amplicon } \\
\text { length }\end{array}$ & $\begin{array}{l}\text { Chromosome region coverage/ } \\
\text { transcription variant specificity }^{\mathrm{a}}\end{array}$ \\
\hline \multicolumn{4}{|l|}{ qRT-PCR } \\
\hline \multirow[t]{2}{*}{ PTPRH } & F: ATGAAGGTCGTGTCTCACTC & $117 \mathrm{bp}$ & $\begin{array}{l}\text { NM_002842.4 } \\
\text { NM_001161440.2 }\end{array}$ \\
\hline & R: CAGGAAGAAAATCAGCAGGC & & \\
\hline$A C T B$ & $\begin{array}{l}\text { F: AGAGCTACGAGCTGCCTGAC } \\
\text { R: AAGGTAGTTTCGTGGATGCC }\end{array}$ & $124 \mathrm{bp}$ & NM_001101.3 \\
\hline \multicolumn{4}{|l|}{ Pyrosequencing } \\
\hline $\begin{array}{l}\text { PTPRH 1st } \\
\text { exon/5' UTR }\end{array}$ & $\begin{array}{l}\text { F: TTGGTAAAGGGGAAATTTTTGAGTGTAA } \\
\text { R: biot-CCTAAAAATCCCTACCTTAAAAAC } \\
\text { S: TGGGATTTTTGGGTT }\end{array}$ & $187 \mathrm{bp}$ & chr19:55720703-55720889 \\
\hline $\begin{array}{l}\text { PTPRH } \\
\text { 5' promoter }\end{array}$ & $\begin{array}{l}\text { F: biot-AGTTTTAGGTTGTTTTTGATGTGTGATTAT } \\
\text { R: CTAAAAATACCTCCCATCCTTTCT } \\
\text { S: AАCCСАСTCСАСТTT }\end{array}$ & $215 \mathrm{bp}$ & chr19:55721009-55721223 \\
\hline \multicolumn{4}{|l|}{ Chip assay } \\
\hline $\begin{array}{l}\text { PTPRH } \\
\text { promoter }\end{array}$ & $\begin{array}{l}\text { F: CTTCCACCTGCTGGACTT TA } \\
\text { R: GTTCCACTTCCTCCTCCT C }\end{array}$ & $99 \mathrm{bp}$ & chr19:55720845-55720943 \\
\hline $\begin{array}{l}\text { PTPRH } \\
\text { exon } 20\end{array}$ & $\begin{array}{l}\text { F: CCAGACCCAAATTCCTTC CT } \\
\text { R: TCCCTAGGTCTTTCCAGG AT }\end{array}$ & 76 bp & chr19:55692800-55692875 \\
\hline $\begin{array}{l}\text { ACTB } \\
\text { promoter }\end{array}$ & $\begin{array}{l}\text { F: ACGCCTCCGACCAGTGTT } \\
\text { R: GCCCAGATTGGGGACAAA }\end{array}$ & $73 b p$ & chr7:5569393-5569465 \\
\hline HBB promoter & $\begin{array}{l}\text { F: GCAATAGATGGCTCTGCCCT } \\
\text { R: GACAGGTACGGCTGTCATCA }\end{array}$ & $132 \mathrm{bp}$ & hr11:5248304-5248435 \\
\hline
\end{tabular}

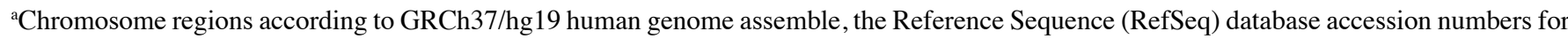
particular transcription variants are provided. F, forward; R, reverse; S, sequencing.

\section{Results}

PTPRH Expression in tissue samples. We searched for tumor specific expression changes of all genes encoding different RPTPs in our previously reported microarray transcriptome data for normal and neoplastic colorectal tissues (18). We found that PTPRH mRNA had the most reduced expression in CRC of all genes encoding RPTPs with a fold change (FC) of

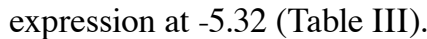

Consistent with this are the comparisons of PTPRH expression in normal colonic samples and CRC in 5 different datasets from the GEO database (26-29) that uniformly showed a significant decrease of PTPRH expression in cancer sections (GSE40967 $\log \mathrm{FC}=-2.18$; GSE25070: $\operatorname{logFC}=-1.4$; $\mathrm{GSE} 44076 \log \mathrm{FC}=-2.79 ; \mathrm{GSE} 21510 \log \mathrm{FC}=-2.97 ; \mathrm{GSE} 32323$ $\log \mathrm{FC}=-2.4)$.

Validating PTPRH expression by qRT-PCR on 24 normal colonic mucosa samples, $46 \mathrm{AD}$ and 26 sections of CRC confirmed a stepwise decrease in mRNA expression through the adenoma-carcinoma sequence (Fig. 1). A significant $(\mathrm{P}<0.0001)$ downregulation with a $\mathrm{FC}=-3.4$ and $\mathrm{FC}=-7.6$ was observed when normal samples were compared to adenoma and cancer samples, respectively (Fig. 1A).
A subsequent analysis of PTPRH protein expression was performed by immunohistochemical staining of 14 paired $\mathrm{CRC}$ /normal mucosa samples and 10 adenomas. Generally, the highest protein expression was observed in the normal mucosa of the colon. The protein was observed in the cytoplasm and membrane of colonic epithelial layer and was clearly polarized. Strong immunoreactivity was observed in cells of the apical epithelium layer and those of the crypt lumen, while in epithelial cells located at the site of lamina muscularis the expression was visibly lower (Fig. 1B). PTPRH expression was lower in each $\mathrm{CRC}$ section as compared to corresponding normal mucosa (Fig. 1B). Immunoreactivity was to some extent deceased in adenomas compared to normal tissue, however, this was not so pronounced when CRCs were compared with normal samples (Fig. 1B). In 7 sections of normal mucosa, PTPRH expression was assessed as strong and in 7 sections as moderate, whereas it was scored as moderate, low and undetected in 5, 8 and 1 of CRC samples, respectively. In adenomas, PTPRH expression was high, moderate and low in 1, 7 and 4 samples, respectively.

Promoter DNA methylation analysis. DNA methylation was assessed in two PTPRH 5' regions, including the upstream 
A

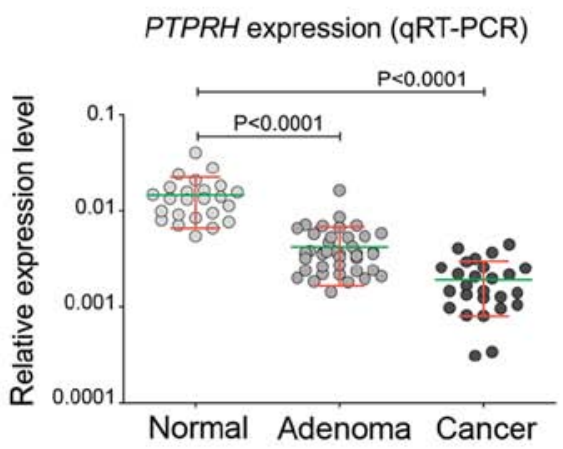

B

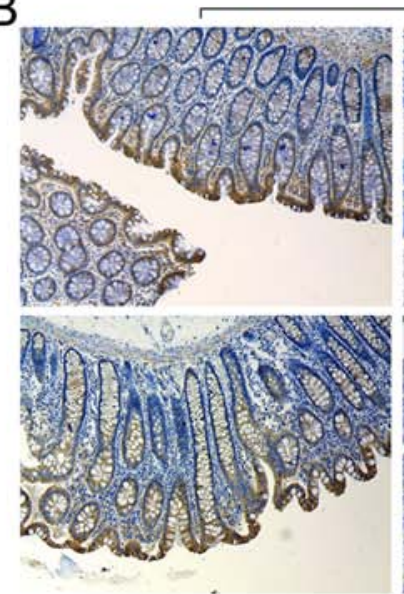

Normal colon

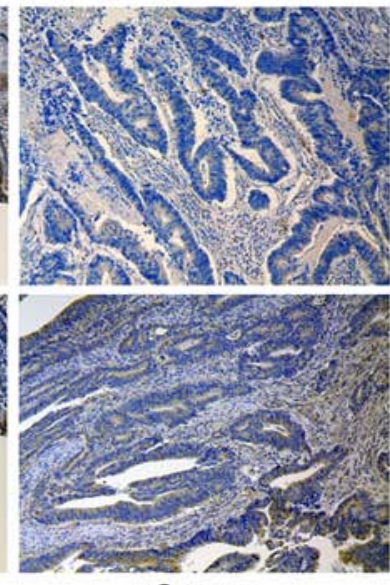

Cancer

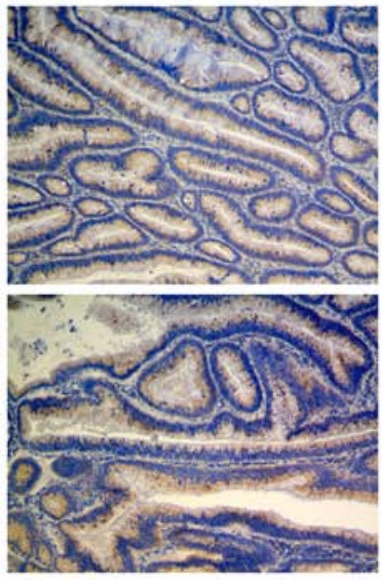

Adenoma

Figure 1. PTPRH expression in colorectal tumors and normal tissue. (A) qRT-PCR analysis of expression levels of PTPRH, mean values and SD are shown as horizontal lines. (B) Examples of immunohistochemical staining of matched normal/CRC samples and adenomas with antibody against PTPRH, magnification, $\mathrm{x} 100$.

Table III. The comparison of expression levels of genes encoding PTPRs in colorectal cancer, adenoma and normal colonic mucosa based on previous microarray transcriptome profiling (14).

\begin{tabular}{llcc}
\hline Gene & $\begin{array}{c}\text { Probset } \\
\text { (Affymetrix U133) }\end{array}$ & $\begin{array}{c}\text { NM vs. CRC } \\
\text { (fold change) }\end{array}$ & $\begin{array}{c}\text { NM vs. AD } \\
\text { (fold change) }\end{array}$ \\
\hline PTPRH & 208300_at & -5.32 & -3.83 \\
PTPRF & 200635_s_at & -3.11 & $-1,69$ \\
PTPRR & 206084_at & -2.57 & -9.75 \\
PTPRO & 211600_at & -2.28 & No difference \\
PTPRCAP & 204960_at & -1.82 & -1.99 \\
PTPRJ & 227396_at & -1.8 & No difference \\
PTRF & 1557938_s_at & 1.92 & No difference \\
PTPRG & 204944_at & 2.98 & 3.07 \\
PTPRS & 229465_a_at & No difference & -1.67 \\
PTPRD & 205712_at & No difference & 2.07 \\
\hline
\end{tabular}

$\mathrm{NM}$, normal mucosa; CRC, colorectal cancer; AD, adenoma.

promoter and 5' UTR/1 exon sequence with pyrosequencing in normal mucosa, AD and CRC samples. Cancer samples demonstrated significantly higher DNA methylation levels for both analyzed 5' gene regions when compared to normal tissue samples (mean $35.21 \%$ and $31 \%$ vs. $15.62 \%$ and $25.35 \% ; \mathrm{P}=0.0007$ and $\mathrm{P}=0.00148$, respectively). Adenomas and normal samples showed comparable DNA methylation levels (Fig. 2).

PTPRH DNA methylation as well as gene and protein expression were assessed in four colorectal cancer cell lines: SW480, HCT116, COLO205 and HT29. qRT-PCR analysis showed variable expression level of PTPRH in these cell lines, with the highest expression in HT29, moderate in COLO205, low in HCT116 and very low in SW480. The mRNA levels closely correspond to PTPRH protein levels in four cell lines as detected by western blot analysis (Fig. 3A).

Analyzing DNA methylation patterns with pyrosequencing showed that gene/protein expression levels were related to methylation levels. The highest and almost complete DNA methylation was observed in both cell lines with low PTPRH levels; SW480 and HCT116. In contrast, COLO205 and HT29 cells demonstrating higher gene expression presented low DNA methylation (Fig. 3B).

These four cell lines were cultured in the presence of DNA methyltrasferases' inhibitor 5-aza-dC. A stepwise gradient of four concentrations $0,2.5,5$ or $10 \mu \mathrm{M}$ of 5 -aza-dC was used in culture. The increased $P T P R H$ expression was observed in SW480 and HCT116, but not in the cell lines that lack DNA methylation at the PTPRH (Fig. 3C). The increased expression after 5-aza-dC treatment was also observed at protein level (Fig. 3D). However, the expression in treated SW480 was still low and required long exposure time when detected with western blotting.

Chromatin modifications at PTPRH promoter. Using chromatin immunoprecipitation, we measured the concentration of RNA II polymerase ( $\mathrm{Pol} 2)$ as well as trimethylation levels of both $\mathrm{K} 4$ of histone $\mathrm{H} 3$ ( $\mathrm{H} 3 \mathrm{~K} 4 \mathrm{~m} 3$, the established marker of transcriptionally active chromatin) and K27 of histone H3 (H3K27m3, the marker of inactive chromatin) at the PTPRH promoter and $3^{\prime}$ region of this gene (exon 20) in $4 \mathrm{CRC}$ cell lines. For comparison, the level of immunoprecipitation was also assessed for the $A C T B$ promoter (transcriptionally active, $\beta$-actin gene) and $H B B$ promoter (transcriptionally inactive, hemoglobin gene).

The pattern of Pol2 and selected histone posttranslational modifications at the gene promoter corresponded to expression and methylation status. A relatively high Pol 2 concentration was observed in the PTPRH promoter region for HT29 and COLO205, i.e. in both cell lines lacking DNA methylation and characterized by high expression. A low Pol2 level was detected at the PTPRH promoter in HCT116 and SW480 that corresponds to the low gene expression (Fig. 4A). 


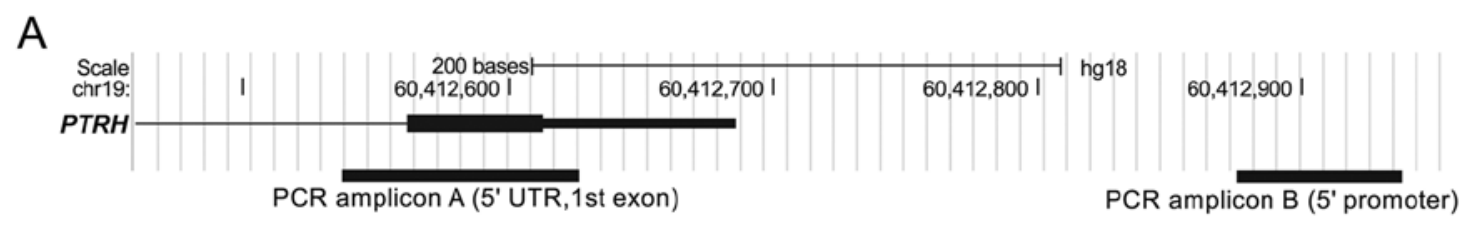

B

PCR amplicon $A$

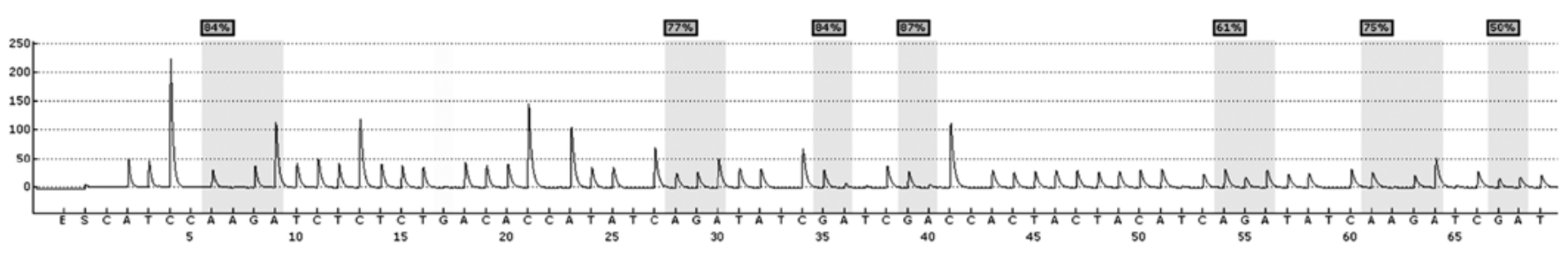

PCR amplicon B

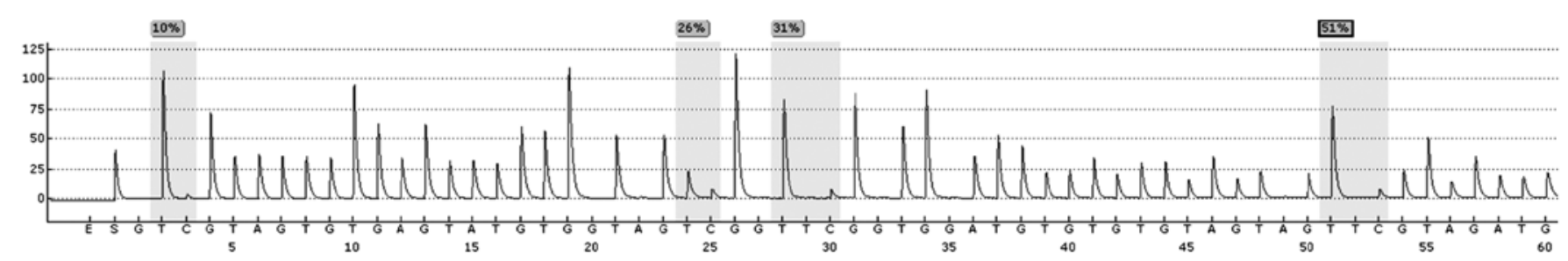

C
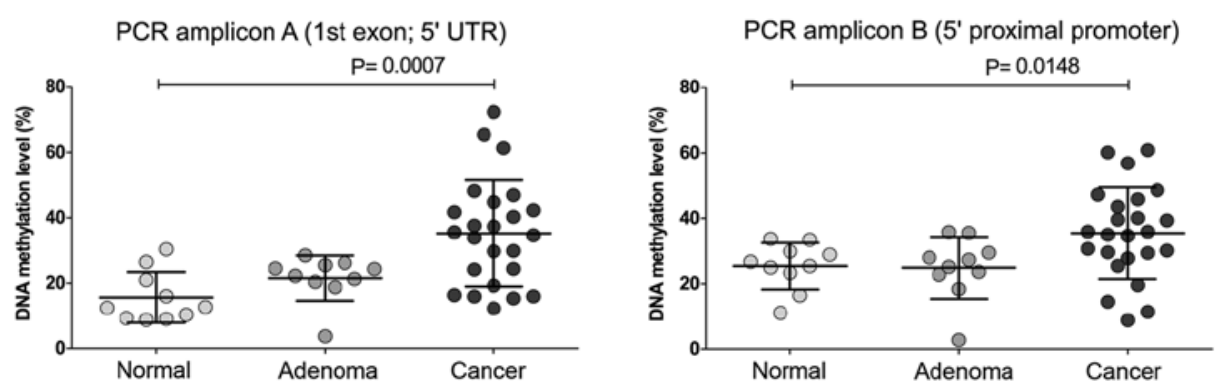

Figure 2. DNA methylation at the PTPRH promoter region in colorectal tumors and normal tissue. (A) The region of interest, including the position of PCR amplicons used for pyrosequencing analysis. (B) Examples of pyrosequencing results for two PCR amplicons in CRC samples. (C) Pyrosequencing analysis of DNA methylation in PTPRH 5' regions, each dot represents the average DNA methylation level of the CpGs within the particular region for a single sample; mean values and SD are shown as horizontal lines.

The level of $\mathrm{H} 3 \mathrm{~K} 4 \mathrm{~m} 3$ at the PTPRH promoter, but not 3 ' region, also clearly corresponded to expression and methylation status. High levels of this modification were observed in HT29 and COLO205, whereas low levels and no enrichment were seen in HCT116 and SW480 (both with the methylated gene promoter) (Fig. 4B). In contrast, the level of $\mathrm{H} 3 \mathrm{~K} 27 \mathrm{~m} 3$ at the PTPRH promoter showed no enrichment in HT29 and COLO205 and somewhat higher levels in HCT116 and SW480. $\mathrm{H} 3 \mathrm{~K} 27 \mathrm{~m} 3$ levels were high at 3 ' gene regions in all the cell lines (Fig. 4C).

\section{Discussion}

The balance between protein tyrosine kinase (PTK) activities and that of protein tyrosine phosphatases (PTPs) is the basis for regulation of intercellular signaling pathways. A lack of this balance affects basic cellular functions: proliferation, adhesion and migration and it plays a role in the pathogenesis of cancer. As a general mechanism, receptor phosphorylation triggers the signaling pathway and results in phosphorylation of the downstream proteins. In turn, protein phosphatases remove phosphate groups and mute signaling. Most proteins of this family are downregulated in cancer by genetic/epigenetic mechanisms $(5,10,14,30)$. However, an oncogenic role of PTPs has also been documented (5).

Of note, PTPRH was previously observed to be expressed in certain CRC derived cell lines and upregulated in CRC tissue from patients, as detected by immunohistochemical staining. In contrast to previous results, we found this gene to be one of the significantly downregulated ones in colorectal tumor compared to normal colonic mucosa. PTPRH downregulation was uniformly observed in five independent datasets of the acquired microarray data. qRT-PCR results confirmed a stepwise decrease of PTPRH expression in AD and CRC sections. Using IHC, we observed that PTPRH is expressed in normal colonic epithelium and the expression pattern has a certain asymmetry in the epithelium cross-section, as previously described (31). Protein expression is low at the lateral border 
A

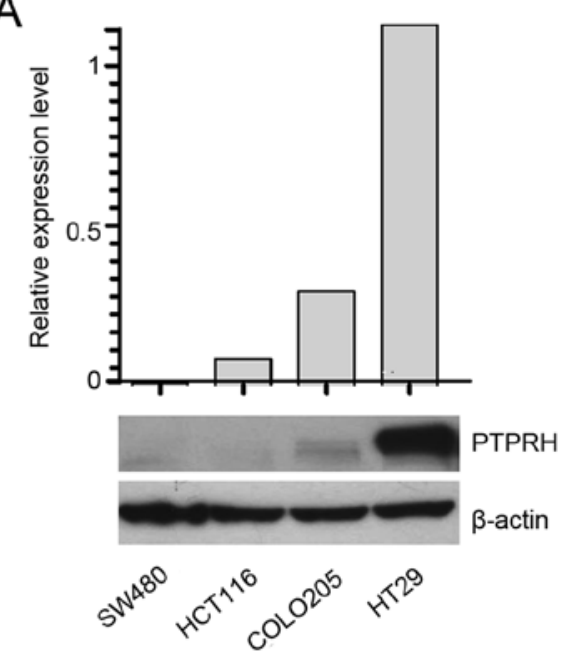

B

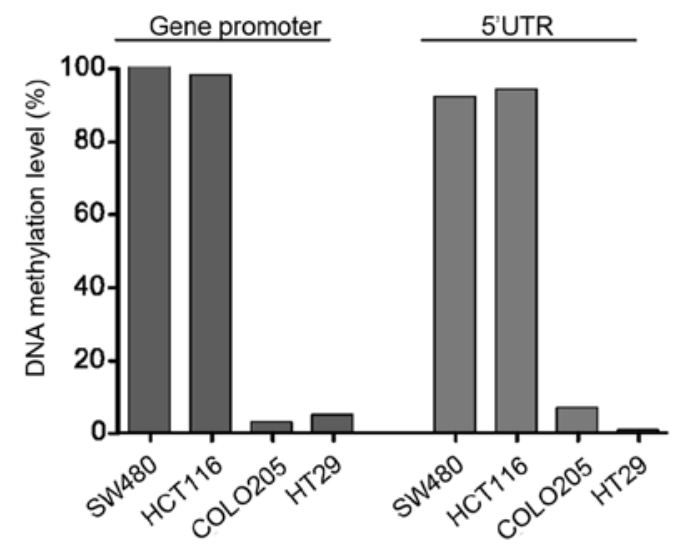

C

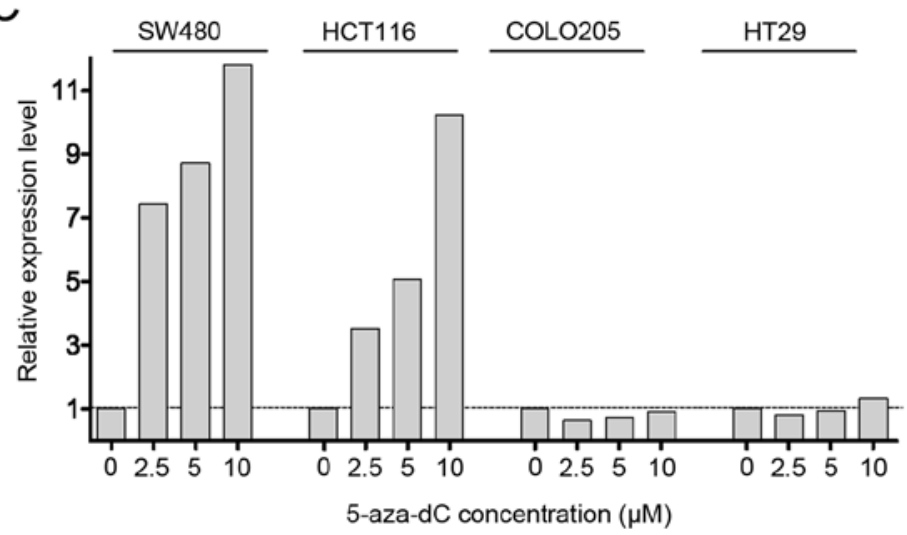

$\mathrm{D}$
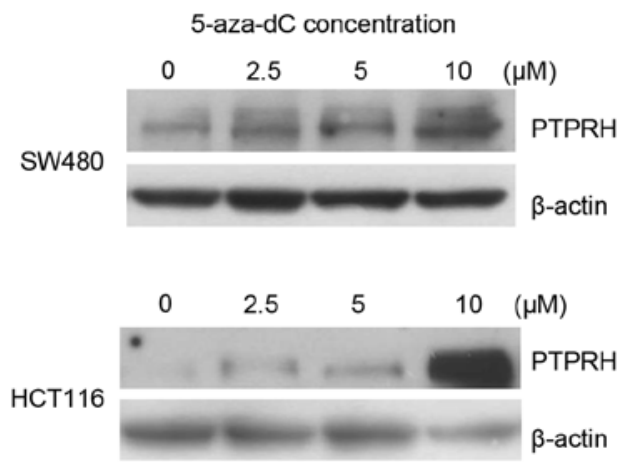

Figure 3. The effect of PTPRH promoter DNA methylation on gene expression in colorectal cancer cell lines. Comparison of $P T P R H$ expression (A) and DNA methylation levels (B) in four cell lines: HCT116, SW480, COLO205 and HT29. (C and D) PTPRH expression levels in colorectal cell lines cultured with various concentrations of DNA methyltransferase inhibitor, 5-Aza-2'-deoxycytidine. Measured by qRT-PCR (C) and western blotting with Ab against PTPRH (D).

but highest at the apical surface of the epithelial layer in the enterocytes that form the brush border. Contrary to that previously reported, our immunohistochemical staining confirmed decreased PTPRH expression in cancer sections compared to matched normal colonic samples.

Epigenetic mechanisms and DNA methylation may contribute to tumor-specific gene downregulation and were previously found to be involved in silencing different RPTPs encoding genes in CRC (32). We assessed DNA methylation levels at the $5^{\prime}$ region of $P T P R H$ in a series of CRC, AD and normal mucosa samples and found increased DNA methylation levels in tumor samples that corresponded with a decrease in gene expression. The effect of DNA methylation at the PTPRH promoter on gene expression was further investigated in CRC cell lines. When two CRC cell lines SW480 and HCT116, characterized by low PTPRH expression and high methylation of the gene 5 ' region, were treated with DNA methylation inhibitor (5-aza-dC), we observed increased gene expression levels. Such an effect was not observed in two cell lines with higher PTPRH expression and an unmethylated promoter. Such results confirm that, similarly to other genes from the PTP family, aberrant epigenetic regulation indeed plays a role in PTPRH downregulation. However, we have to note that some tumor samples showed methylation levels within the range of the normal samples. Probably another mechanism may also be involved as in the case of PTPRJ silencing, where gene downregulation is mediated by both aberrant promoter methylation, genetic deletion and mRNA degradation by upregulated oncogenic miRNA (33).

The finding of PTPRH downregulation in colorectal tumors is consistent with the results from hepatocellular carcinoma where also a decreased expression was found (34). This suggests a suppressive rather than an oncogenic role as was previously proposed (35). The tumor suppressor nature of this phosphatase is also supported by some functional data. PTPRH was found to play a role in contact inhibition of cell growth and motility by dephosphorylating p130 focal adhesion kinase and p62dok (17). Activating FAK-src and p130Cas-JNK signaling cascades promotes cancer progression and invasion (36,37). Cell-cell adhesion induced PTPRH expression and upregulated its activity (17). PTPRH was also found to be involved in MAPK pathway regulation via inhibiting ERK activation in response to LPA and also, to some extent, to EGF substrates (17). Accordingly, PTPRH negatively affected proliferation and inhibited colony formation in culture (17). Recently, large-scale analyses of the 
A

RNA polymerase II enrichment
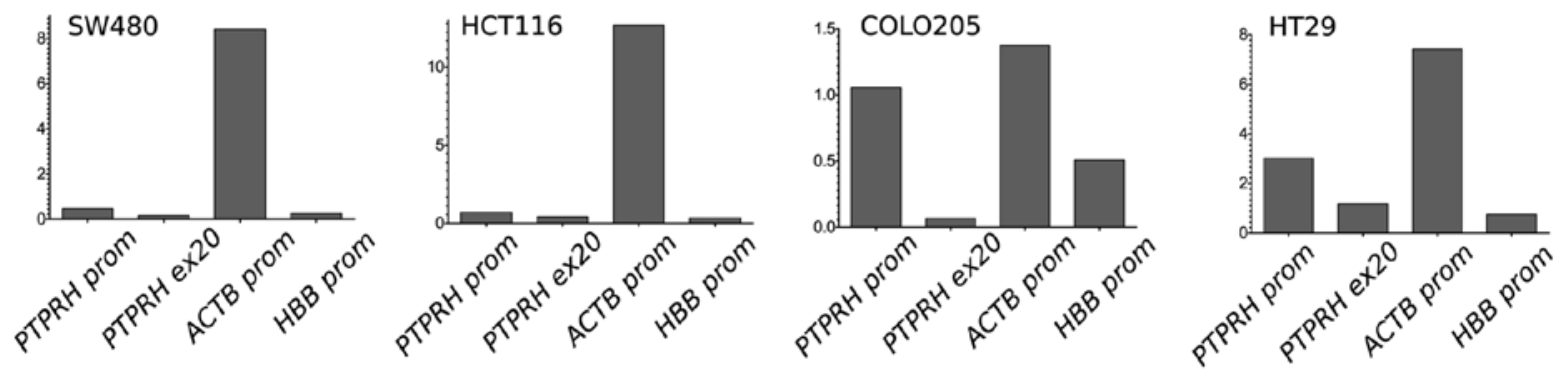

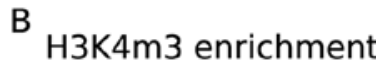
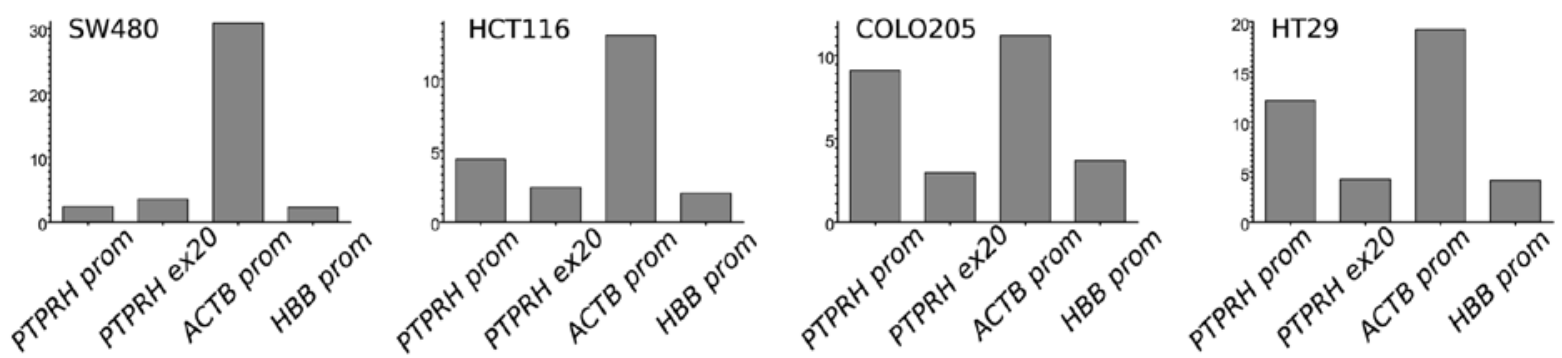

\section{C} SW480
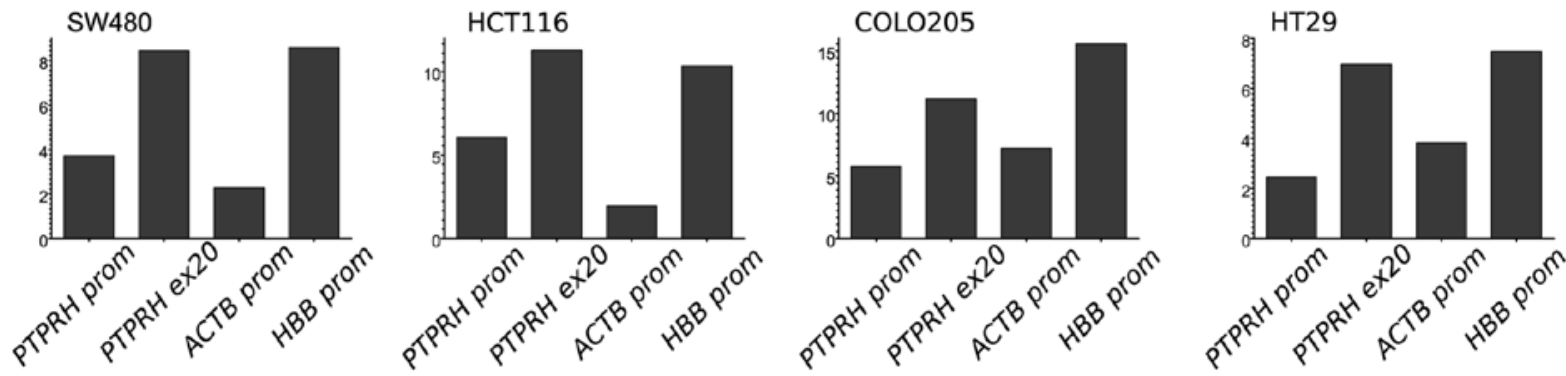

Figure 4. The level of RNA polymerase II binding (A) as well as the levels of H3K4me3 (B) and H3K27me3 (C) at the gene promoter and 3 ' region (exon 20) of $P T P R H$ in four cell lines with diverse gene expression; $A C T B$ and $H B B$ promoters are used as reference chromatin regions that are transcriptionally active and inactive, respectively.

RTK-phosphatase interactome was published. One of the important hits of screening was the interaction between PTPRH and EGFR that was clearly confirmed by coimmunoprecipitation (16). In a functional experiment, where $P T P R H$ expression in HEK293 cells was induced by tetracycline, EGFR dephosphorylation levels were closely related to antibiotic doses. Accordingly, a knockout of this gene in OV-90 cells that express relatively low PTPRH levels increased the basal ERK activation that was also further enhanced upon EGF stimulation (16). The role of PTPRH in regulating apoptosis was also reported. Induced apoptosis was observed in fibroblast cells with PTPRH overexpression as a consequence of modulating PI3K signaling by inactivation of ALK kinase and integrin-linked kinase (ILK) (38). In turn, in activated T cells PTPRH was identified as negative regulator that interact with Lck receptor tyrosine kinase (39).

The previous suggestion that PTPRH may act as an oncogene was based on the observation of protein expression in CRC tissue slides (15) and also on the results from an in vivo model. In mice small intestine with APC mutation, Ptprh deficiency resulted in lower rates of large adenomas $(>2 \mathrm{~mm})$ developing spontaneously in comparison to mice with normal gene expression. However, no such difference was found in the large intestine from mice. No difference in the general number of adenomas and no difference in the proliferation and apoptosis in size-matched tumors from the two groups of animals were observed (31).

Because of the epigenetically-mediated decrease in PTPRH expression in tumor tissue and its involvement in key cancerrelated pathways, this phosphatase could be considered as important for tumorigenesis. However, highly tissue-specific expression of this PTPR have also been observed. In mouse tissue, Ptprh expression was detected in the gastrointestinal tract, especially in the small intestine, but not in other tissues (31). A search of Genotype-Tissue Expression (GTEx) project data (40) that combines RNA-Seq Expression Data from different human tissues, confirms the highest expression of this gene in the small intestine, but shows that it is also expressed at high levels in the spleen, stomach, colon and adrenal gland. These data reveal a striking difference of PTPRH expression 
in different parts of large intestine, being high in the transverse colon and low in the sigmoid part. This may suggest a somewhat different role of this phosphatase in the proximal and distal colon. Irrespectively, $P T P R H$ expression is clearly downregulated in all CRCs, regardless of tumor location. In our qRT-PCR analysis we did not observe a difference in PTPRH levels in CRC from the proximal and distal colon (data not shown). No such difference in PTPRH mRNA levels between differentially located cancers was also found in the deposited GSE18088 dataset (containing samples with clearly prescribed tumor location data).

Contrary to previously reported results, our study shows that PTPRH is downregulated in colorectal tumors. The reduced gene expression in CRC is related to increased promoter methylation and PTPRH expression seem to be epigenetically regulated via DNA methylation and chromatin modifications. Considering the previous studies regarding its role in cell signaling it appears that, similarly to other genes from RPTPs family, PTPRH is a tumor suppressor. The fact that PTPRH directly inhibits EGFR activity upon ligand-mediated stimulation, means that the silencing of this phosphatase represents the almost unexplored mechanism of MAPK pathway activation in colorectal tumors. The clinical relevance of the downregulation of PTPRH as well as inactivation of other genes encoding PTPRs requires further investigation. Loss of PTEN phosphatase, that interacts with EGFR downstream proteins, was documented as prognostic factor for anti-EGFR monoclonal antibody-based therapy in CRC patients (41). In theory, the expression status of EGFRinteracting phosphatases could provide some prognostic value for the outcome of the patients treated with targeted therapy, however this requires further well-designed clinical analysis.

\section{Acknowledgements}

We thank Piotr Hołownia for proofreading the manuscript. This study was supported by the research grant no. IP2011 005471 from the Polish Ministry of Science and Higher Education.

\section{References}

1. Duan G and Walther D: The roles of post-translational modifications in the context of protein interaction networks. PLoS Comput Biol 11: e1004049, 2015.

2. Fleuren EDG, Zhang L, Wu J and Daly RJ: The kinome 'at large' in cancer. Nat Rev Cancer 16: 83-98, 2016.

3. Li X, Wilmanns M, Thornton J and Köhn M: Elucidating human phosphatase-substrate networks. Sci Signal 6: rs10-rs10, 2013.

4. Nikolaienko RM, Agyekum B and Bouyain S: Receptor protein tyrosine phosphatases and cancer: New insights from structural biology. Cell Adhes Migr 6: 356-364, 2012.

5. Hardy S, Julien SG and Tremblay ML: Impact of oncogenic protein tyrosine phosphatases in cancer. Anticancer Agents Med Chem 12: 4-18, 2012.

6. Omerovic J, Clague MJ and Prior IA: Phosphatome profiling reveals PTPN2, PTPRJ and PTEN as potent negative regulators of PKB/Akt activation in Ras-mutated cancer cells. Biochem J 426: 65-72, 2010

7. Zhao Y, Scott A, Zhang P, Hao Y, Feng X, Somasundaram S, Khalil AM, Willis J and Wang Z: Regulation of paxillin-p130-PI3K-AKT signaling axis by Src and PTPRT impacts colon tumorigenesis. Oncotarget: Jul 18, 2016 (Epub ahead of print).

8. Tarcic G, Boguslavsky SK, Wakim J, Kiuchi T, Liu A, Reinitz F, Nathanson D, Takahashi T, Mischel PS, Ng T, et al: An unbiased screen identifies DEP-1 tumor suppressor as a phosphatase controlling EGFR endocytosis. Curr Biol 19: 1788-1798, 2009.
9. Bardelli A, Parsons DW, Silliman N, Ptak J, Szabo S, Saha S, Markowitz S, Willson JK, Parmigiani G, Kinzler KW, et al: Mutational analysis of the tyrosine kinome in colorectal cancers. Science 300: 949, 2003.

10. Korff S, Woerner SM, Yuan YP, Bork P, von Knebel Doeberitz M and Gebert J: Frameshift mutations in coding repeats of protein tyrosine phosphatase genes in colorectal tumors with microsatellite instability. BMC Cancer 8: 329, 2008.

11. Laczmanska I, Skiba P, Karpinski P, Bebenek $M$ and Sasiadek MM: Customized array comparative genomic hybridization analysis of 25 phosphatase-encoding genes in colorectal cancer tissues. Cancer Genomics Proteomics 14: 69-74, 2017.

12. van Roon EHJ, de Miranda NFCC, van Nieuwenhuizen MP, de Meijer EJ, van Puijenbroek M, Yan PS, Huang TH, van Wezel T, Morreau H and Boer JM: Tumour-specific methylation of PTPRG intron 1 locus in sporadic and Lynch syndrome colorectal cancer. Eur J Hum Genet 19: 307-312, 2011.

13. Ashktorab H, Rahi H, Wansley D, Varma S, Shokrani B, Lee E, Daremipouran M, Laiyemo A, Goel A, Carethers JM, et al: Toward a comprehensive and systematic methylome signature in colorectal cancers. Epigenetics 8: 807-815, 2013.

14. Laczmanska I, Karpinski P, Bebenek M, Sedziak T, Ramsey D, Szmida E and Sasiadek MM: Protein tyrosine phosphatase receptor-like genes are frequently hypermethylated in sporadic colorectal cancer. J Hum Genet 58: 11-15, 2013.

15. Seo Y, Matozaki T, Tsuda M, Hayashi Y, Itoh H and Kasuga M: Overexpression of SAP-1, a transmembrane-type protein tyrosine phosphatase, in human colorectal cancers. Biochem Biophys Res Commun 231: 705-711, 1997.

16. Yao Z, Darowski K, St-Denis N, Wong V, Offensperger F, Villedieu A, Amin S, Malty R, Aoki H, Guo H, et al: A global analysis of the receptor tyrosine kinase-protein phosphatase interactome. Mol Cell 65: 347-360, 2017.

17. Noguchi T, Tsuda M, Takeda H, Takada T, Inagaki K, Yamao T, Fukunaga K, Matozaki T and Kasuga M: Inhibition of cell growth and spreading by stomach cancer-associated protein-tyrosine phosphatase-1 (SAP-1) through dephosphorylation of p130cas. J Biol Chem 276: 15216-15224, 2001.

18. Skrzypczak M, Goryca K, Rubel T, Paziewska A, Mikula M, Jarosz D, Pachlewski J, Oledzki J and Ostrowski J: Modeling oncogenic signaling in colon tumors by multidirectional analyses of microarray data directed for maximization of analytical reliability. PLoS One 5: pii: e13091, 2010.

19. Bustin SA, Benes V, Garson JA, Hellemans J, Huggett J, Kubista M, Mueller R, Nolan T, Pfaffl MW, Shipley GL, et al: The MIQE guidelines: Minimum information for publication of quantitative real-time PCR experiments. Clin Chem 55: 611-622, 2009.

20. Van de Sompele J, De Preter K, Pattyn F, Poppe B, Van Roy N, De Paepe A and Speleman F: Accurate normalization of real-time quantitative RT-PCR data by geometric averaging of multiple internal control genes. Genome Biol 3: Research0034, 2002.

21. Muller PY, Janovjak H, Miserez AR and Dobbie Z: Processing of gene expression data generated by quantitative real-time RT-PCR. Biotechnique 32: 1372-1374, 1376, 1378-1379, 2002.

22. Tost $\mathrm{J}$ and Gut IG: DNA methylation analysis by pyrosequencing. Nat Protoc 2: 2265-2275, 2007.

23. Mikula M, Rubel T, Karczmarski J, Statkiewicz M, Bomsztyk K and Ostrowski J: Beads-free protein immunoprecipitation for a mass spectrometry-based interactome and posttranslational modifications analysis. Proteome Sci 13: 23, 2015.

24. Flanagin S, Nelson JD, Castner DG, Denisenko O and Bomsztyk K: Microplate-based chromatin immunoprecipitation method, Matrix ChIP: A platform to study signaling of complex genomic events. Nucleic Acids Res 36: e17, 2008.

25. Barrett T, Wilhite SE, Ledoux P, Evangelista C, Kim IF, Tomashevsky M, Marshall KA, Phillippy KH, Sherman PM, Holko M, et al: NCBI GEO: Archive for functional genomics data sets - update. Nucleic Acids Res 41: D991-D995, 2013.

26. Sanz-Pamplona R, Berenguer A, Cordero D, Molleví DG, Crous-Bou M, Sole X, Paré-Brunet L, Guino E, Salazar R, Santos C, et al: Aberrant gene expression in mucosa adjacent to tumor reveals a molecular crosstalk in colon cancer. Mol Cancer 13: 46, 2014.

27. Marisa L, de Reyniès A, Duval A, Selves J, Gaub MP, Vescovo L, Etienne-Grimaldi MC, Schiappa R, Guenot D, Ayadi M, et al: Gene expression classification of colon cancer into molecular subtypes: Characterization, validation, and prognostic value. PLoS Med 10: e1001453, 2013. 
28. Hinoue T, Weisenberger DJ, Lange CPE, Noushmehr $\mathrm{H}$, Byun H-M, van Dijk CM, Pan F, Malik S, Van Den Berg DJ, Shen H, et al: Abstract LB-173: Genome-scale analysis of aberrant DNA methylation in colorectal cancer. Cancer Res 71 (Suppl 8): LB-173, 2011. doi: 10.1158/1538-7445.AM2011-LB-173.

29. Tsukamoto S, Ishikawa T, Iida S, Ishiguro M, Mogushi K, Mizushima H, Uetake H, Tanaka H and Sugihara K: Clinical significance of osteoprotegerin expression in human colorectal cancer. Clin Cancer Res 17: 2444-2450, 2011.

30. Wang Z, Shen D, Parsons DW, Bardelli A, Sager J, Szabo S, Ptak J, Silliman N, Peters BA, van der Heijden MS, et al: Mutational analysis of the tyrosine phosphatome in colorectal cancers. Science 304: 1164-1166, 2004.

31. Sadakata H, Okazawa H, Sato T, Supriatna Y, Ohnishi H, Kusakari S, Murata Y, Ito T, Nishiyama U, Minegishi T, et al: SAP-1 is a microvillus-specific protein tyrosine phosphatase that modulates intestinal tumorigenesis. Genes Cells 14: 295-308, 2009.

32. Laczmanska I and Sasiadek MM: Tyrosine phosphatases as a superfamily of tumor suppressors in colorectal cancer. Acta Biochim Pol 58: 467-470, 2011.

33. Paduano F, Dattilo V, Narciso D, Bilotta A, Gaudio E, Menniti M, Agosti V, Palmieri C, Perrotti N, Fusco A, et al: Protein tyrosine phosphatase PTPRJ is negatively regulated by microRNA-328. FEBS J 280: 401-412, 2013.

34. Nagano H, Noguchi T, Inagaki K, Yoon S, Matozaki T, Itoh H, Kasuga M and Hayashi Y: Downregulation of stomach cancerassociated protein tyrosine phosphatase-1 (SAP-1) in advanced human hepatocellular carcinoma. Oncogene 22: 4656-4663, 2003.
35. Hoekstra E, Peppelenbosch MP and Fuhler GM: The role of protein tyrosine phosphatases in colorectal cancer. Biochim Biophys Acta 1826: 179-188, 2012.

36. Zhao J and Guan J-L: Signal transduction by focal adhesion kinase in cancer. Cancer Metastasis Rev 28: 35-49, 2009.

37. Van Slambrouck S, Grijelmo C, De Wever O, Bruyneel E, Emami S, Gespach C and Steelant WF: Activation of the FAK-src molecular scaffolds and p130Cas-JNK signaling cascades by alpha1-integrins during colon cancer cell invasion. Int J Oncol 31: 1501-1508, 2007.

38. Takada T, Noguchi T, Inagaki K, Hosooka T, Fukunaga K, Yamao T, Ogawa W, Matozaki T and Kasuga M: Induction of apoptosis by stomach cancer-associated protein-tyrosine phosphatase-1. J Biol Chem 277: 34359-34366, 2002.

39. Ito T, Okazawa H, Maruyama K, Tomizawa K, Motegi S, Ohnishi H, Kuwano H, Kosugi A and Matozaki T: Interaction of SAP-1, a transmembrane-type protein-tyrosine phosphatase, with the tyrosine kinase Lck. Roles in regulation of T cell function. J Biol Chem 278: 34854-34863, 2003.

40. Lonsdale J, Thomas J, Salvatore M, Phillips R, Lo E, Shad S, Hasz R, Walters G, Garcia F, Young N, et al; GTEx Consortium: The Genotype-Tissue Expression (GTEx) project. Nat Genet 45: 580-585, 2013.

41. Wang ZH, Gao QY and Fang JY: Loss of PTEN expression as a predictor of resistance to anti-EGFR monoclonal therapy in metastatic colorectal cancer: Evidence from retrospective studies. Cancer Chemother Pharmacol 69: 1647-1655, 2012. 